\title{
The language barrier
}

\section{Don't let library lingo get in the way of learning}

\author{
by Anne Pemberton and Peter Fritzler
}

$\mathrm{T}$ ake a look at the following sets of terminology:

- Controlled vocabulary, Su Doc, bib record, full-text access, classification scheme, monograph, database

- Wack, that's dope, dubs, off the chain, phat, crib, dude

- Baryon-antibaryon asymmetry, fermion, Higgs boson, muon chamber, vertex detector

All of us understand the first set of terms. We (the authors) happen to understand the first two sets of terms. We're librarians, we're also in our 20 s, and we still watch MTV. Librarians who are parents with teenagers perhaps understand the first two categories, as well. For those who don't know, the second list of terms contains many of the words frequently used by today's traditional college-aged students (18-24 year old). Fabwas used in the ' 60 s to describe what in the ' 70 s was groory and in the ' 80 s became awesome. But what about the third set of words? If you happen to have an interest in high-energy physics, then you probably understand or have at least seen the words in the last category.

Chances are that most readers of this essay will not understand nor be familiar with the words in at least one of the categories of terminology above. We all recognize the first as they are terms we were taught in library school or encountered in our first library jobs. As librarians and library staff, we use these terms almost every day. We use these words with colleagues and they understand exactly what we're talking about. They are ingrained in our vocabulary, and wre rarely give them a second thought. We use these words when we direct patrons at the reference desk and when we provide instruction. We know our terminology and assume the rest of the world does, as well. But do our students understand us?

\section{Finding common ground}

If an instructor came into a classroom and immediately began using the physics terms listed above, most of us would quickly lose interest and our minds would wander. Few instructors could make us stay focused on a class when they were not speaking "our language." We would have an especially hard time if we did not see how the class and its terminology related to our needs directly or if we knew that our grade was not dependent on learning the terminology. We wouldn't understand what the instructor was saying, and most likely, we wouldn't really care. Why should we? How could we? If we had no education or background in physics, how could we possibly be on "the same page" with our instructor?

The imaginary physics instructor above may not realize that the students do not grasp the terms he or she is using. Similarly, it seems as though we, as library professionals, do not understand why the rest of the world doesn't know what we are talking about, often prompting the ques-

\section{About the authors}

Anne Pemberton is public services librarian, e-mail: pembertona@uncw.edu, and Peter Fritzler is outreach and reference librarian, e-mail: fritzlerp@uncwedu, at the University of North Carolina-Wilmington

(c) 2004 Anne Pemberton and Peter Fritzler 
tion, "Don't these people use the library?" We know they do use the library, but as ad hoc users, students cannot possibly be asked to know the lingo of libraries. That is not to say that students do not need to understand the various concepts behind the terminology, but that they need not become "little librarians."

Students are already bogged down with new terminology from their courses and a new way of life (leaving home and coming to college). Why should they be burdened with trying to learn yet another set of terms that they see no need for understanding? What is driving them to understand this terminology? While we seek answers to these and similar questions, we need to find a way to explain library collections and systems to our students while minimizing the use of "library lingo."

Compounding this issue, our students come from more diverse backgrounds than ever before and no two students have the same baseline knowledge of libraries. Many have never set foot in their high school library and some may not have had a high school library to use at all. Many may have used their library but never needed to know the finer points of library lingo. They had no rea- son to do so then, and we believe they really shouldn't be expected to do so in college.

\section{Learning, not lingo}

Perhaps we can find a way to put an end to the heavy use of library lingo in our reference transactions and in our instruction sessions. By no means do we have the answers to this problem right now Many libraries already recognize this problem and have created guides to library lingo for their students (some examples are listed above). We hope to come up with other solutions to this problem with an investigation we are about to begin. We plan on surveying students at the University of North Carolina-Wilmington to find out which libraryrelated terms our students do understand and which ones they do not.

Once we collect this information, we will make sure that all our library staff and faculty are aware of the terms that we all use that are meaningful to our students, and we also hope to share our findings with the profession as a whole. Hopefully, we will be able to better communicate with them and actually teach them only that which they really need to know: how to obtain and evaluate information.

\section{("Building community..." continued frompage 132)} memories and songs during the summer and fall after reading and discussing the play.

Although the schedule of activities has not been completed, conversations with a cross-section of university faculty members who created unique assignments are being held regarding selecting the next book and enhancing the learning experiences.

An English teacher is interested in improving critical thinking activities and getting more faculty to buy into the experience. Another idea is to choose a book by an author who can visit campus and participate in the discussions, thus increasing the glamour of and adding interest to the experience. Also being discussed are determining the best time to present the new title to the faculty in order to ensure that more faculty plan class activities and the need to give administrators an oppor- tunity to lead a discussion to ensure that they do more than just endorse the concept.

The one book, one community experience has not increased the number of books checked out of the O'Kelly Library collection, but because of an aggressive library instruction program and assignments given when instruction is provided, the number of students coming to the reference desk seeking assistance with their assignments has increased.

Projects such as "One Book, One Community" enrich and extend the WSSU learning environment and illustrate to faculty that the library is an innovative campus agency. As a result of advertising their services, projects and availability, librarians are being seen outside of the library. Because of their demonstrated willingness to actively participate in learning experiences, maybe librarians will be given new opportunities to partner in the entire learning process. 